International Journal of Child and Adolescent Resilience

Revue internationale de la résilience des enfants et des adolescents

\title{
Self-Compassion as a Compensatory Resilience Factor for the Negative Emotional Outcomes of Alcohol- Involved Sexual Assault among Undergraduates
}

\author{
N.J. Strickland, C. Wekerle, I.L. Kehayes, K. Thompson, K. Dobson and S.H. \\ Stewart
}

Volume 6, Number 1, 2019

URI: https://id.erudit.org/iderudit/1069076ar

DOI: https://doi.org/10.7202/1069076ar

See table of contents

Publisher(s)

Canada Research Chair in Interpersonal Traumas and Resilience/Chaire de recherche du Canada sur les traumas interpersonnels et la résilience

ISSN

2292-1761 (digital)

Explore this journal

Cite this article

Strickland, N., Wekerle, C., Kehayes, I., Thompson, K., Dobson, K. \& Stewart, S. (2019). Self-Compassion as a Compensatory Resilience Factor for the Negative Emotional Outcomes of Alcohol- Involved Sexual Assault among Undergraduates. International Journal of Child and Adolescent Resilience / Revue internationale de la résilience des enfants et des adolescents, 6(1), 52-69.

https://doi.org/10.7202/1069076ar

\section{Article abstract}

Objectives: Approximately half of sexual assaults involve alcohol; these assaults tend to be more severe and may be more likely to result in negative emotional outcomes like anxiety and depression (Ullman \& Najdowski, 2010). Self-compassion (SC; extending kindness and care towards oneself) may promote resilience from the negative emotional consequences of alcohol-involved sexual assault (AISA). This study examined SC as a resilience factor, testing whether it attenuates and/or counteracts the association between AISA and negative emotional outcomes. Methods: Undergraduate drinkers $(\mathrm{N}=785$ ) completed measures tapping past-term AISA (Kehayes, et al., 2019), SC (i.e., Self-Compassion Scale; Neff, 2003), and anxiety and depression (Kessler et al., 2002). The Self-Compassion Scale was scored as two higherorder domains (self-caring, self-criticism) each with three lower-order facets (self-kindness, mindfulness, and common humanity; over-identification, self-judgment, and isolation). Results: Supporting compensatory effects, the higher-order SC domains showed main effects: the presence of self-caring and relative absence of self-criticism counteracted the adverse effects of AISA on both anxiety and depression. Similarly, the lower-order SC facets showed main effects: the presence of self-kindness and relative absence of overidentification counteracted the adverse effects of AISA on anxiety/depression - with therelative absence of self-judgment and isolation additionally counteracting the effect of AISA on depression. Conclusion: SC works as a compensatory resilience factor for the association between AISA and anxiety/depression. Implications: SC interventions with attention towards increasing self-kindness and decreasing negative facets of SC may be important for negative emotional outcomes in general, including those following AISA.
All Rights Reserved @ $\odot$ N.J. Strickland, C. Wekerle, I.L. Kehayes, K. Thompson, K. Dobson, S.H. Stewart, 2019

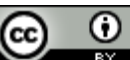

This document is protected by copyright law. Use of the services of Érudit (including reproduction) is subject to its terms and conditions, which can be viewed online.

https://apropos.erudit.org/en/users/policy-on-use/ 


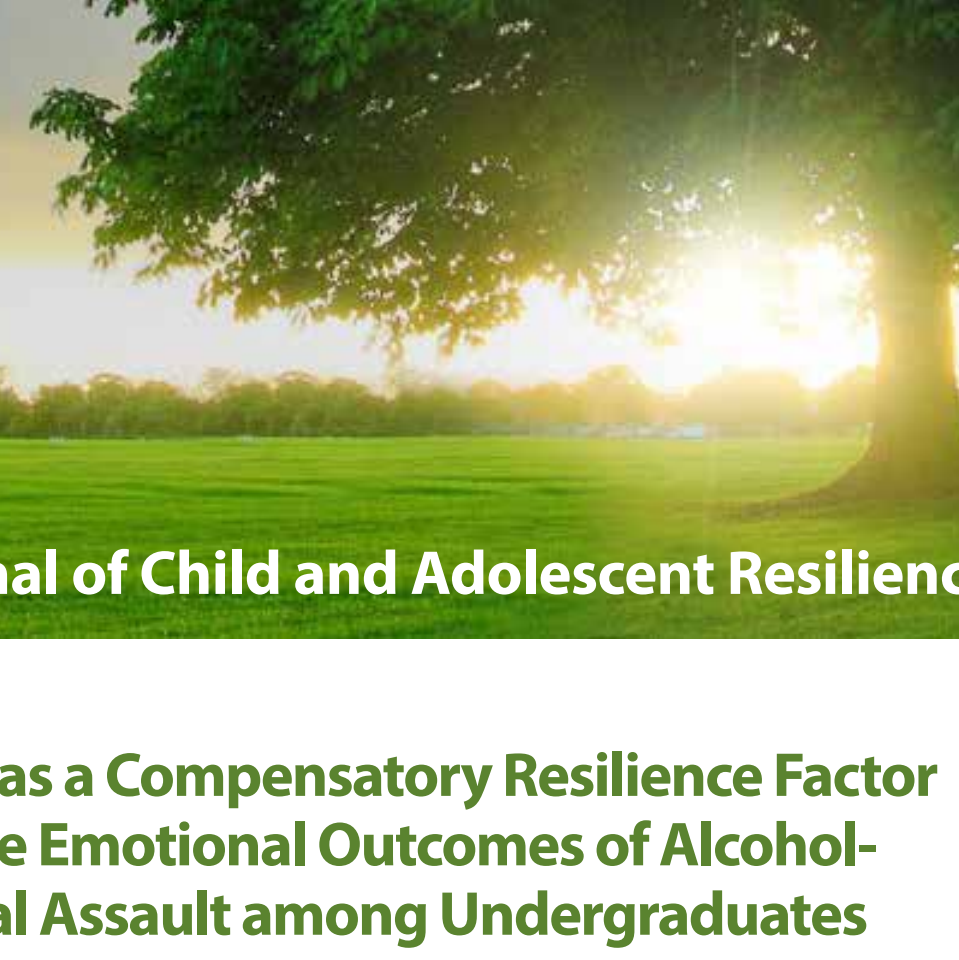

\author{
N.J. Strickland', C. Wekerle², I.L. Kehayes ${ }^{3}$, K. Thompson", \\ K. Dobson ${ }^{5}$ and S.H. Stewart ${ }^{6}$
}

1 M.A., Department of Psychology and Neuroscience, Dalhousie University, Halifax, Nova Scotia, Canada.
2 Ph.D., Department of Pediatrics, McMaster University, Hamilton, Ontario, Canada.
3 B.Sc., Department of Psychology and Neuroscience, Dalhousie University, Halifax, Nova Scotia, Canada.
4 Ph.D., Department of Psychology, St. Francis Xavier, Antigonish, Nova Scotia, Canada.
5 Ph.D., Department of Psychology, University of Calgary, Calgary, Alberta, Canada.
6 Ph.D., Department of Psychiatry, Dalhousie University, Halifax, Nova Scotia, Canada.

Corresponding Author: Dr. Sherry H. Stewart, Dalhousie University. Email: sstewart@dal.ca. Mailing address: Department of Psychiatry, Dalhousie University, 8th Floor Abbie J. Lane Building, 5909 Veterans Memorial Lane, Halifax, NS, Canada, B3H 2 E2.

\title{
Abstract:
}

Objectives: Approximately half of sexual assaults involve alcohol; these assaults tend to be more severe and may be more likely to result in negative emotional outcomes like anxiety and depression (Ullman \& Najdowski, 2010). Self-compassion (SC; extending kindness and care towards oneself) may promote resilience from the negative emotional consequences of alcohol-involved sexual assault (AISA). This study examined SC as a resilience factor, testing whether it attenuates and/or counteracts the association between AISA and negative emotional outcomes.

Methods: Undergraduate drinkers $(\mathrm{N}=785)$ completed measures tapping past-term AISA (Kehayes, et al., 2019), SC (i.e., Self-Compassion Scale; Neff, 2003), and anxiety and depression (Kessler et al., 2002). The Self-Compassion Scale was scored as two higherorder domains (self-caring, self-criticism) each with three lower-order facets (self-kindness, mindfulness, and common humanity; over-identification, self-judgment, and isolation). 
Results: Supporting compensatory effects, the higher-order SC domains showed main effects: the presence of self-caring and relative absence of self-criticism counteracted the adverse effects of AISA on both anxiety and depression. Similarly, the lower-order SC facets showed main effects: the presence of self-kindness and relative absence of overidentification counteracted the adverse effects of AISA on anxiety/depression - with the relative absence of self-judgment and isolation additionally counteracting the effect of AISA on depression.

Conclusion: SC works as a compensatory resilience factor for the association between AISA and anxiety/depression.

Implications: SC interventions with attention towards increasing self-kindness and decreasing negative facets of SC may be important for negative emotional outcomes in general, including those following AISA.

\section{Funding:}

Noelle Strickland is supported by a Doctoral Scholarship from the Social Sciences and Humanities Research Council of Canada (SSHRC), a Killam Doctoral Fellowship, and a Doctoral-level Nova Scotia Graduate Scholarship. Ivy-Lee Kehayes is supported by a Doctoral Scholarship from SSHRC, an Eliza Ritchie Doctoral Fellowship, and an honorary Doctoral-level Scotia Scholar Award from the Nova Scotia Health Research Foundation. Sherry Stewart is supported through a Canadian Institutes of Health Research Tier 1 Canada Research Chair in Addictions and Mental Health. The Caring Campus Project was funded by Movember Canada (Grant \# 35361), H. Stuart, S.-P. Chen, T. Krupa, K. Dobson, S. H. Stewart, and M. Teehan. This work was also funded by a CIHR team grant in sexual violence to C. Wekerle (PI) and S. H. Stewart (col) (Grant \# TE3-138302). P. Davis-MacNevin and J. Swansburg are thanked for their research assistance, and H. Stuart and T. Krupa are thanked for their comments on an earlier version of this manuscript. The authors report no conflict of interest.

\section{Conflict of Interest:}

Authors declare no conflict of interest.

\section{Keywords:}

Self-compassion, Resilience, Alcohol-Involved Sexual Assault, Anxiety, Depression, Negative Emotional Outcomes

\section{Outcomes of Alcohol-Involved Sexual Assault among Undergraduates}

Although sexual assault is often thought to consist of non-consensual sexual contact, a broader definition includes violations of sexual integrity such as threats of sexual 
violence or unwanted contact (Testa, VanZile-Tamsen, Livingston, \& Koss, 2004). Among undergraduates, $6.6 \%$ of women and $3.2 \%$ of men report experiencing sexual assault (Hines, Armstrong, Reed, \& Cameron, 2012). Further, it is estimated that alcohol is used by the perpetrator, victim, or both in about half of sexual assaults (Ullman \& Najdowski, 2010). Alcohol-involved sexual assault (AISA) is particularly relevant to university students as rates of AISA are higher on university campuses than in the broader community, in part due to the high prevalence of heavy drinking on campuses (Howard, Griffin, \& Boekeloo, 2008).

Relative to other sexual assaults, some studies suggest that AISAs tend to be more severe and are more likely to involve multiple perpetrators (Gilbert et al., 2018; Ullman \& Najdowski, 2010). Additionally, AISA victims who were drinking engage in more self-blame, endure more stigma, receive more negative reactions from others following disclosure, and experience more depression compared to sexual assault not involving alcohol and AISA involving perpetrator-only drinking (Littleton, Grills-Taquechel, \& Axsom, 2009; Ullman \& Najdowski, 2010). Intoxication at the time of a sexual assault may dampen the stress response and thus potentially reduce the distress a survivor later experiences (Clum, Nishith, \& Calhoun, 2002). However, subsequent self-blame interpretations (e.g., that they could have avoided the assault if they were not drinking), may exacerbate anxiety and depression in AISA survivors and counteract any protective effect of their drinking at the time of the assault (Littleton et al., 2009; Ullman \& Najdowski, 2010). Thus, exploring resilience factors that mitigate the potential negative emotional consequences that follow AISA is important.

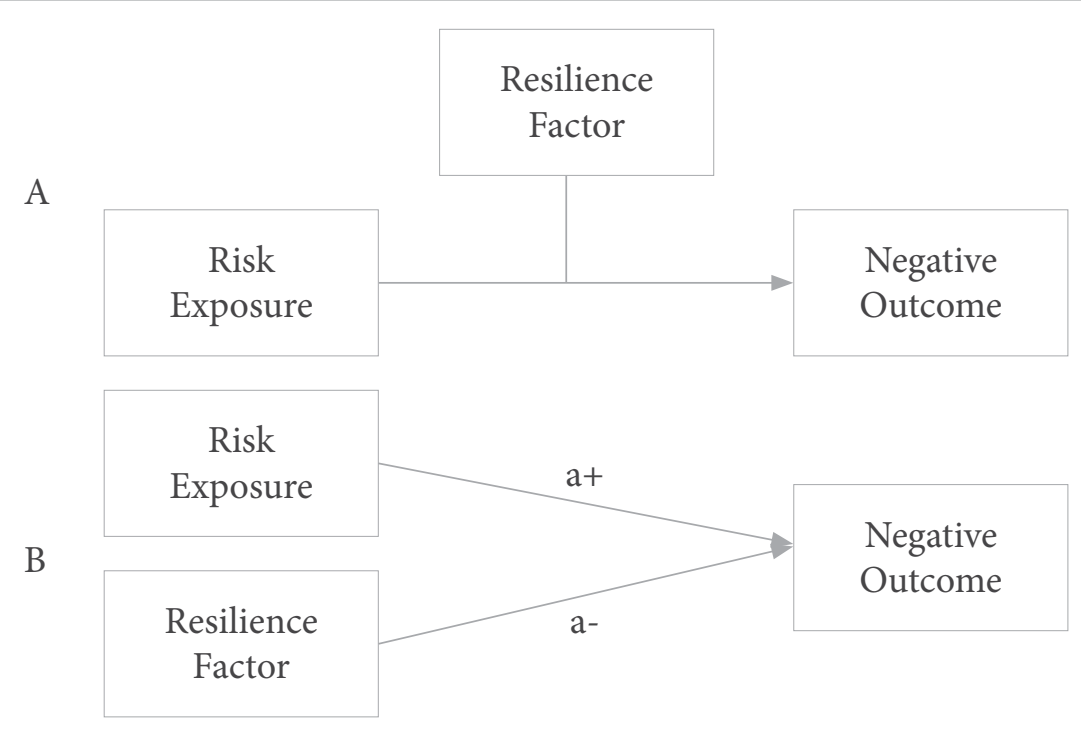

Figure 1. Theoretical models of how a resilience factor exerts its effects: (a) the protective model where the resilience factor interacts with the risk factor to buffer the effects of the risk factor on the adverse outcome; and (b) the compensatory model where the resilience factor exerts a main effect that works in opposition to (i.e., counteracts) the main effect of the risk factor on the adverse outcome. 
Resilience is the process of overcoming or coping adaptively with traumatic experiences and circumventing trajectories that are associated with risk exposure (Fergus \& Zimmerman, 2005; Rutter, 1985). Two alternative models have been proposed for how resilience factors operate (see Figure 1; see Fergus \& Zimmerman, 2005 for a review). The first model is a protective model, where the resilience factor attenuates, or moderates, the association between the risk factor and the negative outcome. One example is high parental support attenuating the link between poverty and violent behaviour such that poverty is more strongly linked to violent behavior in those with low than those with high parental support. The second resilience model is a compensatory model, involving two main effects, where the resilience factor compensates for (i.e., acts in the opposite direction to) the effect of the risk factor on the negative outcome. One example is community resources counteracting the negative effects of child abuse on poor academic achievement. This model would involve main effects of both community resources (the resilience factor) and child abuse (the risk factor) on the outcome of academic achievement. As compared to the protective model where the resilience factor would interact with the risk factor, the compensatory model involves the risk and resilience factor both predicting the same outcome but in opposite directions, such that the resilience factor compensates for the adverse effects of the risk factor (Fergus \& Zimmerman, 2005). This suggests that a compensatory effect may have a general effect as a resilience factor, while a protective factor may work to attenuate the adverse effects of a specific traumatic experience. Thus, compensatory factors might warrant being fostered among all people, and protective factors may be especially relevant for people who have experienced a specific trauma (e.g., AISA; Fergus \& Zimmerman, 2005; Windle, 2011).

\section{Self-Compassion}

Extending compassion toward the self (i.e., "self-compassion"; SC; Neff, 2003a) - might serve as a resilience factor that protects from or compensates for associations between AISA and negative emotional outcomes. Some studies suggest that SC is broadly comprised of two high-order domains: the presence of self-caring and the absence of self-criticism (e.g., Brenner, Heath, Vogel, \& Crede, 2017). Within the higher-order SC domain, there are three components. The first component is self-kindness, which involves providing kindness to the self through benevolent self-talk. The second component is mindfulness, which involves holding painful emotions in balanced awareness. Finally, common humanity is the understanding that one's failures and shortcomings are part of being human. Within the higher-order self-criticism domain, there are also three components: self-judgment (harshness toward the self, critical self-talk), over-identification (over-identifying with, ruminating on, or avoiding painful emotions), and isolation (believing one's failures are isolated to the self), for a total of six facets comprising the overall SC construct (Neff, 2003a). In general, SC is robustly related to less psychopathology such as lower depression and anxiety (MacBeth \& Gumley, 2012).

SC may help AISA victims cope with traumatic events because SC is highly relevant to reducing negative emotional outcomes. Although AISA has not been examined in relation to SC, Neff (2003a) theorized that refraining from self-judgment and self-criticism may allow a person to experience self-kindness, subsequently mitigating the otherwise harmful effects of traumatic experiences. Further, a survivor may engage in more self-care behavior and less 
self-criticism, experience less avoidance coping and ruminative self-blame, and think of the trauma as a painful, rather than a self-defining, experience (Zeller, Yuval, Nitzan-Assayag, \& Bernstein, 2015). Together, these SC-relevant processes may facilitate natural exposure to trauma-related cues and thus promote a faster recovery from trauma among AISA survivors (Thompson \& Waltz, 2008). Further, although SC is often conceptualized as an individual difference (Neff, Rude, \& Kirkpatrick, 2007) there is evidence that it can be increased (e.g., Mindful SC; Neff \& Germer, 2013). Altogether, SC is a resilience factor that could be targeted in treatment with AISA survivors.

Although no studies have examined the role of SC as a resilience factor for experiences of AISA and negative emotional outcomes, results from related areas support that it may act as a protective resilience factor. In one study, SC moderated the association between shame and eating disorder severity, such that shame was related to more severe eating disorder symptoms only among those with low SC (Ferreira, Matos, Duarte, \& Pinto-Gouveia, 2014). In another study, SC attenuated the association between exposure to negative events and feelings of shame and embarrassment, in that negative events showed stronger associations with shame and embarrassment for those with low (vs. high) SC (Leary, Tate, Adams, Allen, Hancock, \& Carver, 2007). This may have been due to SC helping individuals perceive the negative event as not their fault (Leary et al., 2007). SC also attenuated negative emotional reactions to ambiguous social feedback provided after participants gave a speech (Leary et al., 2007). Similar patterns may be at play in AISA as SC may protect victim-drinking AISA survivors from experiencing subsequent negative emotional effects. In fact, in a study of traumatized adolescents, higher levels of SC at baseline predicted lower depressive, suicidal, panic, and post-traumatic stress disorder (PTSD) symptoms at follow-up (Zeller et al., 2015). However, moderation could not be examined because Zeller et al's (2015) study did not include non-traumatized adolescents.

Given these findings and the dearth of research examining SC in the context of AISA, this study examined AISA and the role of SC as a resilience factor. It was hypothesized that: (1) the experience of AISA would be positively related to anxiety and depression, (2) SC would be negatively related to anxiety and depression, and (3) SC would attenuate the effect of AISA on anxiety and depression. Support for the third hypothesis through this interactive effect would favor the protective model of SC as a resilience factor for survivors of AISA. Main effects but no interactive effects would favor the compensatory model. The role of the six specific SC facets (e.g., the presence of self-kindness, the relative absence of isolation) as well as the higher-order domains of SC (i.e., the presence of self-caring and relative absence of self-criticism) were also explored as resilience factors given recent research suggesting that specific SC facets may be differentially tied to mental health outcomes (Valdez \& Lilly, 2016).

\section{Method}

\section{Participants}

Respondents were a pooled sample of $\mathrm{N}=1,315$ Canadian first and second year undergraduates who completed one of two surveys administered at different time points as 
part of a larger longitudinal study. The first time point was in the fall semester of 2016 and the second in the winter semester of 2017. Students who completed the survey at both time points had only their first survey included, and students who completed the survey at the second time point were only included if they had not completed the first survey. In order to be included in the present analysis, the participant had to report drinking in the past term.

Independent sample t-tests and chi square tests between the two cohorts of drinkers showed no significant differences between cohorts on age or gender. Additionally, chi square tests showed that the proportion who reported past-term drinking (i.e., 60\%; $n=789$ ) did not differ significantly between cohorts. Thus, cohort one and cohort two participants were combined into a single sample. Four respondents were dropped due to identification of their gender as "other" ( $\mathrm{n}=3$; too small a group to permit reliable gender comparison), or to missing data on the victim-drinking AISA item $(n=1)$. The final combined sample of $n=$ 785 was $75.2 \%$ female and $24.8 \%$ male, and the mean age was $18.9(\mathrm{SD}=1.5)$ years.

\section{Procedure}

As part of the larger multi-site Movember-funded Caring Campus Project (see Stuart, Chen, Krupa, Narain, Horgan, Dobson, \& Stewart, 2019), two waves of survey data were collected; data relevant to the current project were only collected at the Dalhousie University site. In the first wave (Fall 2016), all first-year students were sent an invitation email to complete a 30-minute online survey as were second-year students who had completed at least one prior survey in the longitudinal study. In the second wave (Winter 2017), all first- and second-year students who had completed a prior survey were sent an invitation email. Three reminder emails were sent on a weekly basis. Participants were also recruited through oncampus posters, newsletters, and social media advertisements. Both cohorts were included in the present analysis. The response rate to the email recruitment was $35 \%$, similar to other Canadian undergraduate surveys (e.g., American College Health Association, 2013). Participants were compensated with their choice of a $\$ 5$ gift card, a $0.5 \%$ course-credit in a participating psychology course, or a cash value donation of their compensation to oncampus mental health promotion and alcohol harm reduction activities. This study was approved by an institutional Research Ethics Board.

\section{Measures}

Self-Compassion Scale (SCS; Neff, 2003b). This 26-item measure consists of two higher-order domains and six lower-order facets. The first higher-order domain, self-caring, comprised three lower-order subscales: 1) self-kindness (e.g., "I try to be loving towards myself when I am feeling emotional pain"), 2) mindfulness (e.g., "When something upsets me, I try to keep my emotions in balance"), and 3) common humanity (e.g." "I try to see my failings as part of the human condition"). The second higher-order domain, self-criticism, comprised the remaining three subscales: 4) self-judgment (e.g., "When times are really difficult, I tend to be tough on myself"), 5) over-identification (e.g., "When I'm feeling down I tend to obsess and fixate on everything that's wrong," and 6) isolation (e.g., "When I fail at something that's important to me, I tend to feel alone in my failure;" Neff, 2003b). Each item 
is rated on a 5 -point Likert scale ( $1=$ never to $5=$ almost always). We used the means of these six lower-order subscales as well as two higher-order self-caring and self-criticism scales (means of the positive and negative items) in analyses in order to examine more general aspects of the positive and negative domains of the SC construct, as well as the more specific SC facets, as resilience factors. This scoring is supported through a recent factor analytic study showing that a bifactor structure involving these six lower-order facets and two higherorder domains provided the best fit for the SCS (Brenner et al., 2017). All SCS facet and domain scales showed acceptable to excellent internal consistency $(\alpha)$ in the present sample (facets: self-kindness $=.84$; mindfulness $=.75$; common humanity $=.78$; self-judgment $=.83$; isolation $=.80$; over-identification $=.79$; domains: $\mathrm{SC}=.90$; self-criticism $=.92$ ).

Alcohol-Involved Sexual Assault. Past term AISA was measured using the item: "As a result of using alcohol... I was taken advantage of sexually," rated on a 6-point scale from 0 (never) to 5 (more than 10 times). This item was part of a larger questionnaire assessing a variety of potential harms associated with drinking used in a separate study (Chinneck et al., 2018). AISA was dichotomized (never [0] vs. once or more [1]), since frequency was positively skewed. This AISA item was correlated with anxiety and depression in a previous study measured using the Mood and Anxiety Symptoms Questionnaire, indicative of its validity (cf., Kehayes et al., 2019).

Kessler Psychological Distress Scale. This 10-item measure assesses emotional distress on a scale of 1 (none) to 5 (all of the time) over the last 30 days (K10; Kessler et al., 2002). For the present study, we used the sum of the 4-item anxiety subscale (possible range 4-20) and the sum of the 6-item depression subscale (possible range 6-30). Separation of these two subscales has been supported by previous factor analytic results (Brooks, Beard, \& Steel, 2006; Chinneck et al., 2018). In the present sample, Cronbach's alphas were .79 and .89 for the anxiety and depression scales, respectively.

\section{Data Analysis}

Multivariate regression analyses $(\mathrm{N}=785)$ were tested using SPSS version 24 . All dependent and predictor variables were within the acceptable ranges of normality (Kim, 2013; West, Aiken, \& Krull, 1996), residuals appeared to be normally distributed (examined using a P-P plot), and variance appeared to be constant (examined using a scatterplot of standardized residuals and standardized predicted values). Data were screened for outliers using boxplots, but no values were more than three times the inter-quartile range. The Durbin-Watson value was above the suggested cut-off of 1.50 for all models, satisfying the independent errors assumption. No variables were correlated higher than $\mathrm{r}=.75$, all Tolerance values were above .20 , and all variance inflation factor values were below 10 , suggesting no problematic multicollinearity among variables (Schroeder, Lander, \& Levine-Silverman, 1990).

Hypotheses were tested using a set of four multivariate hierarchical regression models. Each model added gender as a covariate in block one, the main effects of the predictors in block two, and the interaction terms in block three. AISA was effect-coded (i.e., -1 and 1) in order to create interaction terms (West et al., 1996) and all predictor variables were meancentered for interpretation. The first two models tested AISA, the positively (self-caring) 
Table 1: Inter-Correlations Among Study Variables $(N=785)$

\begin{tabular}{|c|c|c|c|c|c|c|c|c|c|c|c|c|c|c|c|}
\hline & & $M$ & $S D$ & 1 & 2 & 3 & 4 & 5 & 6 & 7 & 8 & 9 & 10 & 11 & 12 \\
\hline 1 & AISA (\% Yes) & 6.1 & -- & -- & -.01 & -.05 & -.01 & -.03 & -.03 & .02 & -.02 & -.01 & .06 & $.09^{*}$ & -.02 \\
\hline 2 & Self-kindness & 2.89 & .82 & & -- & $.69^{* *}$ & $.57^{* *}$ & $-.51^{* *}$ & $-.36^{* *}$ & $-.37^{* *}$ & $.89^{* *}$ & $-.45^{* *}$ & $-.35^{* *}$ & $-.45^{* *}$ & .03 \\
\hline 3 & Mindfulness & 3.18 & .75 & & & -- & $.65^{* *}$ & $-.30^{* *}$ & $-.31^{* *}$ & $-.25^{* *}$ & $.88^{* *}$ & $-.32^{* *}$ & $-.23^{* *}$ & $-.35^{* *}$ & $.11^{*}$ \\
\hline 4 & $\begin{array}{l}\text { Common } \\
\text { Humanity }\end{array}$ & 3.07 & .82 & & & & -- & $-.23^{* *}$ & $-.22^{* *}$ & $-.23^{* *}$ & $.84^{* *}$ & $-.25^{* *}$ & $-.16^{* *}$ & $-.30^{* *}$ & .04 \\
\hline 5 & $\begin{array}{l}\text { Self- } \\
\text { judgment }\end{array}$ & 3.30 & .89 & & & & & -- & $.73^{* *}$ & $.73^{* *}$ & $-.42^{* *}$ & $.90^{* *}$ & $.41^{* *}$ & $.52^{* *}$ & $-.13^{* *}$ \\
\hline 6 & $\begin{array}{l}\text { Over- } \\
\text { identification }\end{array}$ & 3.23 & .93 & & & & & & -- & $.70^{* *}$ & $-.34^{* *}$ & $.90^{* *}$ & $.42^{*}$ & $.48^{* *}$ & $-.17^{* *}$ \\
\hline 7 & Isolation & 3.20 & .93 & & & & & & & -- & $-.34^{* *}$ & $.90^{* *}$ & $.36^{* *}$ & $.51 * *$ & $-.08^{*}$ \\
\hline 8 & Self-caring & 3.03 & .69 & & & & & & & & -- & $-.40^{* *}$ & $-.29 * *$ & $-.43^{* *}$ & .06 \\
\hline 9 & $\begin{array}{l}\text { Self-criticism } \\
\text { domain }\end{array}$ & 3.24 & .82 & & & & & & & & & - & $.43^{* *}$ & $.55^{* *}$ & $-.13^{* *}$ \\
\hline 10 & Anxiety & 9.66 & 3.26 & & & & & & & & & & -- & $.63^{* *}$ & $-.14^{* *}$ \\
\hline 11 & Depression & 13.47 & 5.30 & & & & & & & & & & & -- & $-.17^{* *}$ \\
\hline 12 & Gender (\% F) & 75.2 & -- & & & & & & & & & & & & -- \\
\hline
\end{tabular}

and negatively (self-criticism) worded SC domains as predictors in the second block, and the interactions between AISA and positively (self-caring) and negatively (self-criticism) worded SC domains in the third block, with anxiety and depression as the outcomes, respectively. The third and fourth models tested AISA and each of the six SCS facets in the second block, and the six AISA - SCS facet interactions in the third block, with depression and anxiety as the outcomes, respectively.

\section{Results}

\section{Descriptive Statistics}

Means, standard deviations, and correlations were examined (see Table 1). About six percent (6.1\%) of participants endorsed past-term AISA. Based on Cohen's (1992) classification of correlations as small $(\mathrm{r}=.10-.29)$, moderate $(\mathrm{r}=.30-.49)$ and large $(\mathrm{r}>.50)$, there were small significant positive associations between AISA and depression and small significant negative associations between mindfulness and anxiety, and common humanity and anxiety. All other significant associations were moderate except for large positive associations between self-judgment, isolation, and over-identification with depression, and a large negative association between self-kindness and depression. Gender differences were observed as overall self-criticism, self-judgment, over-identification, and isolation 
Table 2: Hierarchical Multivariate Regression Model with Positive and Negative Self-Compassion Domains Predicting Anxiety ( $\mathrm{N}=785)$.

\begin{tabular}{|c|c|c|c|c|c|c|c|c|c|c|c|}
\hline & & \multirow[t]{2}{*}{ B } & \multirow[t]{2}{*}{ SE } & $95 \%$ & $\mathrm{Cl}$ of $\mathrm{B}$ & \multirow[t]{2}{*}{$p$} & \multirow[t]{2}{*}{$\beta$} & \multirow{2}{*}{$\begin{array}{l}\text { Overall } \\
\text { Block F }\end{array}$} & \multirow[t]{2}{*}{$\mathbf{R}^{2}$} & \multirow[t]{2}{*}{$\Delta R^{2}$} & \multirow[t]{2}{*}{$\Delta F$} \\
\hline & & & & LL & UL & & & & & & \\
\hline $\begin{array}{l}\text { Block } \\
\text { one }\end{array}$ & Gender & -1.08 & .27 & -1.60 & -.55 & .000 & -.14 & $16.26^{* * *}$ & .02 & & \\
\hline \multirow{4}{*}{$\begin{array}{l}\text { Block } \\
\text { two }\end{array}$} & Gender & -.63 & .24 & -1.10 & -.15 & .010 & -.08 & $53.31^{* * *}$ & .21 & $.19^{* *}$ & $64.35^{* *}$ \\
\hline & AISA & .81 & .43 & -.04 & 1.66 & .062 & .06 & & & & \\
\hline & Self-caring & -.63 & .16 & -.95 & -.31 & .000 & -.13 & & & & \\
\hline & Self-criticism & 1.47 & .14 & 1.20 & 1.75 & .000 & .37 & & & & \\
\hline
\end{tabular}

Notes. ${ }^{*} p<.05 ;{ }^{* *} p<.01 ;{ }^{* * *} p<.001 . \mathrm{B}=$ unstandardized beta coefficients; $\mathrm{SE}=$ standard error; $\mathrm{LL}=$ lower limit of $\mathrm{Cl}$ of $\mathrm{B}, \mathrm{UL}=$ upper limit of $\mathrm{Cl}$ of $\mathrm{B} ; \beta=$ standardized betas; $\Delta \mathrm{R} 2=$ change in $\mathrm{R} 2 ; \Delta \mathrm{F}=$ change in $\mathrm{F}$ statistic. AISA = past-term alcohol-involved sexual assault $(0=$ no; $1=$ yes). Self-caring and self-criticism assessed with Self-Compassion Scale (SCS; Neff, 2003b). Anxiety assessed with K10 (Kessler et al., 2002). Gender: 1 = female, 2 = male.

Table 3: Hierarchical Multivariate Regression Model with Positive and Negative Self-Compassion Domains Predicting Depression ( $\mathrm{N}=785)$.

\begin{tabular}{|c|c|c|c|c|c|c|c|c|c|c|c|}
\hline & & \multirow[t]{2}{*}{ B } & \multirow[t]{2}{*}{ SE } & $95 \%$ & Cl of $B$ & \multirow[t]{2}{*}{$p$} & \multirow[t]{2}{*}{$\boldsymbol{\beta}$} & & \multirow[t]{2}{*}{$\mathbf{R}^{2}$} & \multirow[t]{2}{*}{$\Delta \mathbf{R}^{2}$} & \multirow[t]{2}{*}{$\Delta \mathbf{F}$} \\
\hline & & & & LL & UL & & & Block F & & & \\
\hline $\begin{array}{l}\text { Block } \\
\text { one }\end{array}$ & Gender & -2.05 & .43 & -2.90 & -1.20 & .000 & -.17 & $22.42^{* * *}$ & .03 & & \\
\hline \multirow{4}{*}{$\begin{array}{l}\text { Block } \\
\text { two }\end{array}$} & Gender & -1.11 & .35 & -1.80 & -.42 & .002 & -.09 & $113.73^{* * *}$ & .37 & $.34^{* *}$ & $140.18^{* *}$ \\
\hline & AISA & 1.83 & .63 & .59 & 3.06 & .004 & .08 & & & & \\
\hline & Self-caring & -1.87 & .24 & -2.34 & -1.41 & .000 & -.24 & & & & \\
\hline & Self-criticism & 2.84 & .20 & 2.45 & 3.24 & .000 & .44 & & & & \\
\hline
\end{tabular}

Notes. ${ }^{*} p<.05 ;{ }^{* *} p<.01 ;{ }^{* * *} p<.001 . \mathrm{B}=$ unstandardized beta coefficients; $\mathrm{SE}=$ standard error; $\mathrm{LL}=$ lower limit of $\mathrm{Cl}$ of $B, U L=$ upper limit of $C I$ of $B ; \beta=$ standardized betas; $\Delta R^{2}=$ change in $R^{2} ; \Delta F=$ change in $F$ statistic. AISA = past-term alcohol-involved sexual assault $(0=$ no; $1=$ yes). Self-caring and self-criticism assessed with Self-Compassion Scale (SCS; Neff, 2003b). Depression assessed with K10 (Kessler et al., 2002). Gender: $1=$ female, $2=$ male.

were higher in females and mindfulness was higher in males. Thus, gender was added as a covariate in all regression models.

\section{Models Involving Self-Caring and Self-Criticism Domain Scores}

Results from the model that predicted anxiety (Table 2) showed significant main effects of gender in the first block, and significant main effects of self-caring and self-criticism and a marginal main effect of AISA in the second block of predictors. Female, as opposed to male, 
Table 4: Hierarchical Multivariate Model with AISA and Six Self-Compassion Facets Predicting Anxiety $(\mathrm{N}=785)$.

\begin{tabular}{|c|c|c|c|c|c|c|c|c|c|c|c|}
\hline & & \multirow[t]{2}{*}{ B } & \multirow[t]{2}{*}{ SE } & $95 \%$ & $\mathrm{Cl}$ of $\mathrm{B}$ & \multirow[t]{2}{*}{$p$} & \multirow[t]{2}{*}{$\beta$} & \multirow{2}{*}{$\begin{array}{l}\text { Overall } \\
\text { Block F }\end{array}$} & \multirow[t]{2}{*}{$\mathbf{R}^{2}$} & \multirow[t]{2}{*}{$\Delta R^{2}$} & \multirow[t]{2}{*}{$\Delta \mathbf{F}$} \\
\hline & & & & LL & UL & & & & & & \\
\hline $\begin{array}{l}\text { Block } \\
\text { one }\end{array}$ & Gender & -1.08 & .27 & -1.60 & -.55 & .000 & -.14 & $16.26^{* * *}$ & .02 & & \\
\hline \multirow{8}{*}{$\begin{array}{l}\text { Block } \\
\text { two }\end{array}$} & Gender & -.64 & .24 & -1.11 & -.16 & .009 & -.09 & $30.40^{* * *}$ & .23 & $.21^{* *}$ & $31.78^{* *}$ \\
\hline & AISA & .89 & .43 & .05 & 1.73 & .040 & .07 & & & & \\
\hline & Self-kindness & -.98 & .20 & -1.37 & -.59 & .000 & -.25 & & & & \\
\hline & Mindfulness & .18 & .21 & -.24 & .60 & .405 & .04 & & & & \\
\hline & $\begin{array}{l}\text { Common } \\
\text { humanity }\end{array}$ & .18 & .17 & -.15 & .51 & .291 & .05 & & & & \\
\hline & $\begin{array}{l}\text { Self- } \\
\text { judgement }\end{array}$ & .33 & .20 & -.07 & .74 & .102 & .09 & & & & \\
\hline & $\begin{array}{l}\text { Over- } \\
\text { identification }\end{array}$ & .86 & .18 & .51 & 1.20 & .000 & .24 & & & & \\
\hline & Isolation & .15 & .17 & -.19 & .49 & .397 & .04 & & & & \\
\hline
\end{tabular}

Notes. ${ }^{*} p<.05 ;{ }^{* *} p<.01 ;{ }^{* * *} p<.001$. B: unstandardized beta coefficients; $\mathrm{SE}$ : standard error; $\mathrm{Cl}$ of $\mathrm{B}$ : $\mathrm{LL}=$ lower limit, $\mathrm{UL}=$ upper limit; $\beta$ : standardized betas; $\Delta \mathrm{R}^{2}, \Delta \mathrm{F}$ : change in $\mathrm{R}^{2}$ and $\mathrm{F}$ statistic. AISA: past-term alcohol-involved sexual assault $(0=$ no; $1=$ yes). Self-kindness, mindfulness, common humanity, self-judgement, over-identification, and isolation assessed with Self-Compassion Scale (SCS; Neff, 2003b). Anxiety assessed with K10 (Kessler et al., 2002). Gender: $1=$ female, 2 = male.

gender was associated with higher anxiety, AISA was marginally positively associated with anxiety, the presence of self-caring and the relative absence of self-criticism were negatively associated with anxiety. Together, these three main effects and gender showed significant associations with anxiety, $\mathrm{F}(3,784)=67.93, \mathrm{p}<.001$, and explained about $21 \%$ of the variance in anxiety scores. The addition of the interaction terms failed to add significant incremental variance in explaining anxiety scores $\left(\Delta \mathrm{R}^{2}=.00, \mathrm{p}>.05\right)$, suggesting no moderation. Thus, the block two model was retained as the final model (Field, 2013).

Results from the model with depression as the outcome (see Table 3) showed that there were significant effects of gender in the first block, and significant main effects of AISA, selfcaring, and self-criticism in the second block of predictors. Female gender and AISA were positively associated with depression, and the presence of self-caring and the relative absence of self-criticism were negatively associated with depression. Together, these three main effects plus gender showed significant associations with depression, $\mathrm{F}(3,785)=147.25, \mathrm{p}<.001$, and explained about $36 \%$ of the variance in depression scores. The interaction terms failed to add significant incremental variance $\left(\Delta \mathrm{R}^{2}=.00, \mathrm{p}>.05\right)$, suggesting no moderation. Thus, the block two model was retained as the final model (Field, 2013).

\section{Models Involving the Six SCS Facet Score}

Results from the model with anxiety as the outcome (see Table 4) showed that in the first block, gender was a significant predictor, and in the second block of predictors, there 
Table 5: Hierarchical Multivariate Model with AISA and Six Self-Compassion Facets Predicting Depression $(\mathrm{N}=785)$.

\begin{tabular}{|c|c|c|c|c|c|c|c|c|c|c|c|}
\hline & & \multirow[t]{2}{*}{ B } & \multirow[t]{2}{*}{ SE } & $95 \%$ & $\mathrm{Cl}$ of $\mathrm{B}$ & \multirow[t]{2}{*}{$p$} & \multirow[t]{2}{*}{$\beta$} & \multirow{2}{*}{$\begin{array}{l}\text { Overall } \\
\text { Block F }\end{array}$} & \multirow[t]{2}{*}{$\mathbf{R}^{2}$} & \multirow[t]{2}{*}{$\Delta R^{2}$} & \multirow[t]{2}{*}{$\Delta \mathbf{F}$} \\
\hline & & & & LL & UL & & & & & & \\
\hline $\begin{array}{l}\text { Block } \\
\text { one }\end{array}$ & Gender & -2.05 & .43 & -2.90 & -1.20 & .000 & -.17 & $22.42^{* * *}$ & .03 & & \\
\hline \multirow{8}{*}{$\begin{array}{l}\text { Block } \\
\text { two }\end{array}$} & Gender & -1.23 & .36 & -1.93 & -.53 & .001 & -.10 & $58.83^{* * *}$ & .37 & $.34^{* *}$ & $62.28^{* *}$ \\
\hline & AISA & 1.79 & .63 & .55 & 3.02 & .005 & .08 & & & & \\
\hline & Self-kindness & -1.36 & .29 & -1.94 & -.79 & .000 & -.21 & & & & \\
\hline & Mindfulness & -.20 & .31 & -.82 & .42 & .525 & -.03 & & & & \\
\hline & $\begin{array}{l}\text { Common } \\
\text { humanity }\end{array}$ & -.30 & .25 & -.79 & .19 & .225 & -.05 & & & & \\
\hline & $\begin{array}{l}\text { Self- } \\
\text { judgment }\end{array}$ & .78 & .30 & .19 & 1.37 & .010 & .13 & & & & \\
\hline & $\begin{array}{l}\text { Over- } \\
\text { identification }\end{array}$ & .68 & .26 & .17 & 1.18 & .009 & .12 & & & & \\
\hline & Isolation & 1.26 & .26 & .76 & 1.76 & .000 & .22 & & & & \\
\hline
\end{tabular}

Notes. ${ }^{*} p<.05 ; * * p<.01 ; * * * 0<.001$. B: unstandardized beta coefficients; $\mathrm{SE}$ : standard error; $\mathrm{Cl}$ of $\mathrm{B}$ : $\mathrm{LL}=$ lower limit, $\mathrm{UL}=$ upper limit; $\beta$ : standardized betas; $\Delta \mathrm{R}^{2}, \Delta \mathrm{F}$ : change in $\mathrm{R}^{2}$ and $\mathrm{F}$ statistic. AISA: past-term alcohol-involved sexual assault $(0=$ no; $1=$ yes). Self-kindness, mindfulness, common humanity, self-judgement, over-identification, and isolation assessed with Self-Compassion Scale (SCS; Neff, 2003b). Depression assessed with K10 (Kessler et al., 2002). Gender: $1=$ female, $2=$ male.

was a main effect of AISA. Results showed positive associations between female gender and anxiety and AISA and anxiety. Additionally, self-kindness was negatively associated with anxiety as was the relative absence of over-identification, even after controlling for the other lower-order SC facets, AISA, and gender. This main effect only model with anxiety as the outcome explained a significant $24 \%$ of the variance in anxiety scores, $F(7,780)=33.28, \mathrm{p}$ $<.001$. The interaction terms failed to add significant incremental variance in explaining anxiety scores $\left(\Delta \mathrm{R}^{2}=.01, \mathrm{p}>.05\right)$, suggesting no moderation. Thus, the block two model was retained as the final model (Field, 2013).

Results from the model with depression as the outcome (see Table 5) showed a significant main effect of gender in block one and a main effect of AISA in block two. Namely, female gender and AISA were positively associated with depression. Additionally, self-kindness and the relative absence of self-judgment, over-identification, and isolation were negatively associated with depression in block two even after controlling for the other lower-order SC facets, AISA, and gender. This main effect only model explained a significant $37 \%$ of the variance in depression scores, $\mathrm{F}(7,780)=64.90, \mathrm{p}<.001$. The addition of the interaction terms failed to add significant incremental variance in explaining depression scores $\left(\Delta \mathrm{R}^{2}=.00, \mathrm{p}>.05\right)$, suggesting no moderation. Thus, the block two model was retained as the final model (Field, 2013). 


\section{Discussion}

This study examined the roles of SC as a resilience factor in the association between AISA and anxiety and depression. The first hypothesis that AISA would be positively related to anxiety and depression was supported in that there were small associations between AISA and anxiety and depression. The second hypothesis that SC would be negatively related to both depression and anxiety was supported. Finally, the third hypothesis that high SC would moderate the association between AISA and depression and anxiety - was not supported. Instead, results supported the compensatory resilience model in that there were main effects of both SC and AISA predicting anxiety and depression, with SC exerting effects in an opposing direction to the effects of AISA.

Of this sample of past-term drinkers, 6.1\% reported experiencing AISA. AISA was positively related to depression and anxiety, consistent with previous studies showing that sexual victimization in general is associated with greater depression and anxiety (Xu et al., 2013) and that victim-drinking AISA is associated with high levels of distress including high levels of depression (Ullman \& Najdowski, 2010). Additionally, results are consistent with previous studies showing direct inverse associations between SC and negative emotional outcomes (Ehret, Joormann, \& Berking, 2015; Hoge et al., 2013; Krieger, Altenstein, Baettig, Doerig, \& Holtforth, 2013; MacBeth \& Gumley, 2012; Trompetter, de Kleine, Bohlmeijer, 2017).

Expanding on the current literature by examining SC and AISA together, this study showed opposing main effects of both AISA and SC domains/facets on negative emotional outcomes. Specifically, findings showed the two higher-order domains of SC - the presence of self-caring and relative absence of self-criticism - both compensated for (i.e., worked in opposition to) the adverse effects of AISA on depression and anxiety. Results showed similar patterns in the more nuanced analyses of the six SCS facets (i.e., the presence of selfkindness, mindfulness, and common-humanity; and the relative absence of self-judgment, over-identification, and isolation). The presence of self-kindness and the relative absence of over-identification counteracted the significant adverse effects of AISA on both anxiety and depression. Additionally, the relative absence of self-judgment and of isolation also counteracted against, or worked in opposition to, the adverse effect of AISA on depression. This pattern of results is consistent with the compensatory model of resilience (Fergus \& Zimmerman, 2005), especially in light of the lack of significant interactive effects of SC and AISA on negative emotional outcomes - support for which would have suggested a protective model of resilience. Altogether, these results suggest that everyone, including but not limited to AISA survivors, may benefit from SC interventions given that SC is associated with decreased anxiety and depression.

\section{Self-Criticism Facets and Negative Emotional Outcomes}

The relative absence of the self-criticism facets of self-judgment, over-identification, and isolation compensated for the effect of AISA on depression. Overall these three facets of SC appear to have repetitive, negative thoughts about the self, or rumination, in common (Raes, 2010). Other work has shown that rumination mediates the association between 
SC and depression after controlling for anxiety (Raes, 2010) and that increases in SC are associated with lower depression via decreases in rumination (Krieger et al., 2013). Similarly, the current results suggest that the relative absence of over-identification compensated for the adverse effect of AISA on anxiety, which may indicate the role of both worry and rumination. Worry and rumination have both been shown to mediate the association between SC and anxiety, with worry having the strongest effect (Raes, 2010). Together, the relative absence of certain lower-order negative SC facets may be associated with lower depression and anxiety via less unproductive, repetitive thought (Raes, 2010).

The relative absence of isolation counteracted the adverse effect of AISA on depression (but not anxiety). Social support is important for the well-functioning of sexual assault survivors (Borja, Callahan, \& Long, 2006). Survivors of AISA may feel more loneliness and social isolation than survivors who experience non-alcohol involved sexual assault or perpetrator-drinking AISA, as AISA survivors tend to receive more negative reactions to their disclosures (Ullman \& Najdowski, 2010). Additionally, given societal victim-blaming notions that survivors could have avoided sexual assault had they not been drinking, AISA survivors may be less likely to disclose their assault, further increasing isolation (Weiss, 2010). The lack of effects of isolation on anxiety indicates the compensatory effect of the relative absence of isolation is more important for depression, consistent with the wellestablished link of perceived isolation to depression (Matthews et al., 2016). These results highlight the potential benefits of reducing isolation for survivors of AISA which may increase feelings of social connectedness and ultimately reduce depressive affect.

Findings that the relative absence of self-judgment counteracted the effect of AISA on depression (but not anxiety) is not surprising given the conceptual links of self-judgment to self-blame and the established links of self-blame to depression (Frazier, 1991; Janoff-Bulman, 1979). Although no studies have examined this possibility, self-judgment and self-blame are conceptually related in that they both involve criticizing the self for past behaviours, thoughts, and/or emotions, and they both may lead to guilt or shame (Bensimon, 2017; Weiss, 2010). Reduced self-judgment may foster the ability of AISA survivors to absolve themselves of guilt for their traumatic experience which may in turn lessen feelings of depression.

\section{Self-Compassion Facets and Negative Emotional Outcomes}

Self-kindness compensated for the effect of AISA on both depression and anxiety, which may relate to the emotion regulatory benefits of self-kindness. The self-soothing aspect of self-kindness may provide emotional regulatory benefits for people experiencing the negative emotional outcomes of AISA. Previous studies found that SC is associated with emotion regulation (see Trompetter et al., 2017; Vettese, Dyer, Li, \& Wekerle, 2011) and the link between low SC and PTSD was mediated by emotion dysregulation (Scoglio et al., 2015). Together, this suggests that rumination, worry, social isolation, self-blame, and/or emotion dysregulation may be important processes helping to explain the role of specific SC facets as compensatory resilience factors in the face of traumatic experiences such as AISA.

This study indicates that SC interventions may be a promising avenue to explore in compensating for the negative emotional consequences of AISA - as well as for students 
experiencing anxiety and depression symptoms in general, given the main effects of SC domains and facets on anxiety and depression. Currently, there are various self-caring and compassion-centered interventions that have been empirically explored (see Kirby, 2017 for a review), with the most well-developed being compassion-focused therapy (Gilbert, 2014; Leaviss \& Uttley, 2015). Although compassion-focused therapy includes a SC component and does increase SC in uncontrolled intervention studies (e.g., Beaumont, Irons, Rayner, \& Dagnall, 2016; Gilbert \& Procter, 2006), SC is not the primary focus of the therapy. In contrast, mindful SC is a therapy that specifically addresses SC (Neff \& Germer, 2013). Evidence for the efficacy of mindful SC in increasing SC includes a brief three-week mindful SC intervention study with female undergraduates. Mindful SC, compared to a time-management control, resulted in higher SC immediately post-intervention (Smeets, Neff, Alberts, \& Peters, 2014). Additionally, a randomized control trial (RCT) showed that an eight-week mindful SC intervention resulted in increases in SC and lower depression and anxiety six weeks later, compared to a wait-list control (Neff \& Germer, 2013). Further, a randomized controlled trial of a mindful SC intervention compared to medical treatment-as-usual showed that SC increased, and depression decreased, immediately following the treatment, and these effects were maintained three months later (Friis, Johnson, Cutfield, \& Consedine, 2016).

The present results must be interpreted in light of study limitations and strengths. One important limitation is that the cross-sectional design of the study precludes assessment of directionality and causality, for example whether SC precedes and contributes to reduced anxiety and depression and/or whether lower anxiety and depression precede and contribute to high SC. Longitudinal studies will be required in future to explore the directionality question. Additionally, while we tested the protective and compensatory models, other models of the relations between our study variables are possible and could be explored in future. For example, it is possible that AISA leads to low SC which in turn contributes to anxiety and depression (i.e., SC as a mediator).

Another limitation includes restricted power given the relatively low rate of AISA reported in the sample. Relatedly, another limitation was the assessment of victim-drinking AISA with a single item that did not measure assault severity. Moreover, the AISA item used wording that may have captured participants with less severe assault experiences, and/or only those who perceived drinking as a causal factor in their sexual assault. While validity of our measure is suggested through its links with depression and anxiety in this and prior research (Kehayes et al., 2019), future studies should use multi-item behaviorally-based measures of victim-drinking AISA. An additional limitation was our exclusive focus on victim-drinking AISA without comparison to perpetrator-drinking AISA or non-alcohol-involved sexual assault. However, prior research suggests that victim-drinking AISA survivors tend to experience heightened self-blame and depression (Ullman \& Najdowski, 2010), making the present research particularly relevant to this group of sexual assault survivors.

Finally, our study focused exclusively on anxiety and depression as emotional outcomes of victim-drinking AISA, while survivors may display other maladaptive responses (e.g., PTSD; Ullman \& Filipas, 2001; drinking to cope post-assault; Littleton et al., 2009). In addition, neither history of sexual abuse nor other traumatic events was measured and 
thus their influence could not be controlled; consequently, anxiety and depression may be the result of childhood sexual abuse experiences and not the AISA given their high co-occurrence (Amado, Arce, \& Herraiz, 2015). Similarly, self-esteem was not measured; however, prior research suggests that $\mathrm{SC}$ is related to emotional distress even after controlling for self-esteem (Neff, 2003b).

Despite these limitations, an important strength of this study is that it is the first to examine SC as a resilience factor in the association between AISA exposure and negative emotional outcomes. By suggesting the compensatory role of SC in this context, this study fills an important gap identified in the trauma literature (Zeller et al., 2015). This study identified which particular SC facets play compensatory roles in the case of the relations of AISA with both depression and anxiety, thus identifying which particular SC facets should be targeted in interventions to reduce students' experiences of anxiety and depression generally, but also for AISA victims specifically.

\section{References}

American College Health Association. (2013). American College Health Association-National College Health Assessment II: Canadian Reference Group Data Report Spring. Hanover, MD: American College Health Association. Retrieved from: https://www.acha.org/documents/ncha/NCHA-II\%20SPRING\%202016\%20 CANADIAN\%20REFERENCE\%20GROUP\%20DATA\%20REPORT.pdf.

Amado, B., Arce, R., \& Herraiz, A. (2015). Psychological injury in victims of child sexual abuse: A meta-analytic review. Psychosocial Intervention, 24, 49-62. doi: 10.1016/j.psi.2015.03.002

Beaumont, E., Irons, C., Rayner, G., \& Dagnall, N. (2016). Does compassion-focused therapy training for health care educators and providers increase self-compassion and reduce self-persecution and self-criticism? Journal of Continuing Education in the Health Professions, 36, 4-10. doi: 10.1097/CEH.0000000000000023

Bensimon, M. (2017). Victimization in light of self-compassion: Development towards communal compassion. Aggression and Violent Behavior, 35, 44. doi: 10.1016/j.avb.2017.06.002

Borja, S. E., Callahan, J. L., \& Long, P. J. (2006). Positive and negative adjustment and social support of sexual assault survivors. Journal of Traumatic Stress, 19, 905-914. doi: 10.1002/jts.20169

Brenner, R., Heath, P., Vogel, D., \& Credé, M. (2017). Two is more valid than one: Examining the factor structure of the Self-Compassion Scale (SCS). Journal of Counseling Psychology, 64, 696-707. doi: 10.1037/cou0000211

Brooks, R. T., Beard, J., \& Steel, Z. (2006). Factor structure and interpretation of the K10. Psychological Assessment, 18, 62-70. doi: 10.1037/1040-3590.18.1.62

Chinneck, A., Thompson, K., Dobson, K. S., Stuart, H., Teehan, M., Stewart, S. H., \& The Caring Campus Team. (2018). Neurotic personality traits and risk for adverse alcohol outcomes: Chained mediation through emotional disorder symptoms and drinking to cope. Substance Use \& Misuse, 53, 1730-1741. doi: 10.1080/10826084.2018.1432647

Clum, G., Nishith, P., \& Calhoun, K. (2002). A preliminary investigation of alcohol use during trauma and peritraumatic reactions in female sexual assault victims. Journal of Traumatic Stress, 15, 321-328. doi: 10.1023/A:1016255929315

Cohen, J. (1992). A power primer. Psychological Bulletin, 112, 155-159. doi: 10.1037/0033-2909.112.1.155

Ehret, A., Joormann, J., \& Berking, M. (2015). Examining risk and resilience factors for depression: The role of self-criticism and self-compassion. Cognition and Emotion, 29, 1496-1504. doi: 10.1080/02699931.2014.992394

Field, A. (2013). Discovering statistics using IBM SPSS Statistics (4th ed). West Sussex, UK: Wiley. 
Fergus, S., \& Zimmerman, M. A. (2005). Adolescent resilience: A framework for understanding healthy development in the face of risk. Annual Review of Public Health, 26, 399-419. doi: 10.1146/annurev. publhealth.26.021304.144357

Ferreira, C., Matos, M., Duarte, C., \& Pinto-Gouveia, J. (2014). Shame memories and eating psychopathology: The buffering effect of self-compassion. European Eating Disorders Review, 22, 487-494. doi: 10.1002/erv.2322

Frazier, P. A. (1991). Self-blame as a mediator of post-rape depressive symptoms. Journal of Social and Clinical Psychology, 10, 47-57. doi: 10.1521/jscp.1991.10.1.47

Gilbert, P. (2014). The origins and nature of compassion-focused therapy. British Journal of Clinical Psychology, 53, 6-41. doi: 10.1111/bjc.12043

Gilbert, P., \& Procter, S. (2006). Compassionate mind training for people with high shame and self-criticism. Clinical Psychology and Psychotherapy, 13, 353-379. doi: 10.1002/cpp.507

Gilbert, L., Sarvet, A. L., Wall, M., Walsh, K., Reardon, L., Wilson, P., ... \& Mellins, C. A. (2018). Situational contexts and risk factors associated with incapacitated and nonincapacitated sexual assaults among college women. Journal of Women's Health, 28, 185-193. doi: 10.1089/jwh.2018.7191

Hines, D. A., Armstrong, J. L., Reed, K. P., \& Cameron, A. Y. (2012). Gender differences in sexual assault victimization among college students. Violence and Victims, 27, 922-940. doi: 10.1891/0886-6708.27.6.922

Hoge, E. A., Hölzel, B. K., Marques, L., Metcalf, C. A., Brach, N., Lazar, S. W., \& Simon, N. M. (2013). Mindfulness and self-compassion in generalized anxiety disorder: Examining predictors of disability. Evidence-Based Complementary and Alternative Medicine, 2013, 1-7. doi: 10.1155/2013/576258

Howard, D. E., Griffin, M. A., \& Boekeloo, B. O. (2008). Prevalence and psychosocial correlates of alcoholrelated sexual assault among university students. Adolescence, 43, 733-750. Retrieved from: http:// web.b.ebscohost.com.ezproxy.library.dal.ca/ehost/pdfviewer/pdfviewer?vid=1\&sid=24eccb8b-881b4929-94b4-b1b21f9b391e\%40sessionmgr120.

Janoff-Bulman, R. (1979). Characterological versus behavioral self-blame: Inquiries into depression and rape. Journal of Personality and Social Psychology, 37, 1798-1809. doi: 10.1037/0022-3514.37.10.1798

Kehayes, I. L., Hudson, A., Thompson, K., Wekerle, C., \& Stewart, S. H. (2019). The consequences of alcoholinvolved sexual victimization in male and female college students. Canadian Journal of Community Mental Health, 37, 127-143.

Kessler, R. C., Andrews, G., Colpe, L. J., Hiripi, E., Mroczek, D. K., Normand, SI.-L. T., ...Zaslavsky, A. M. (2002). Short screening scales to monitor population prevalences and trends in non-specific psychological distress. Psychological Medicine, 32, 959-976. doi: 10.1017/S0033291702006074

$\mathrm{Kim}, \mathrm{H}$. (2013). Statistical notes for clinical researchers: Assessing normal distribution using skewness and kurtosis. Restorative Dentistry and Endodontics, 38, 52-54. doi: 10.5395/rde.2013.38.1.52

Kirby, J. N. (2017). Compassion interventions: The programs, the evidence, and implications for research and practice. Psychology and Psychotherapy, 90, 432-455. doi: 10.1111/papt.12104

Krieger, T., Altenstein, D., Baettig, I., Doerig, N., \& Holtforth, M. (2013). Self-compassion in depression: Associations with depressive symptoms, rumination, and avoidance in depressed outpatients. Behavior Therapy, 44, 501-513. doi: 10.1016/j.beth.2013.04.004

Leary, M., Tate, E., Adams, C., Allen, A., Hancock, J., \& Carver, C. S (2007). Self-compassion and reactions to unpleasant self-relevant events: The implications of treating oneself kindly. Journal of Personality and Social Psychology, 92, 887-904. doi: 10.1037/0022-3514.92.5.887

Leaviss, J., \& Uttley, L. (2015). Psychotherapeutic benefits of compassion-focused therapy: An early systematic review. Psychological Medicine, 45, 927-945. doi: 10.1017/S0033291714002141

Littleton, H., Grills-Taquechel, A., \& Axsom, D. (2009). Impaired and incapacitated rape victims. Violence and Victims, 24, 439-457. doi: 10.1891/0886-6708.24.4.439

MacBeth, A., \& Gumley, A. (2012). Exploring compassion: A meta-analysis of the association between selfcompassion and psychopathology. Clinical Psychology Review, 32, 545-552. doi: 10.1016/j.cpr.2012.06.003 
Matthews, T., Danese, A., Wertz, J., Odgers, C. L., Ambler, A., Moffitt, T. E., \& Arseneault, L. (2016). Social isolation, loneliness, and depression in young adulthood: A behavioral genetic analysis. Social Psychiatry and Psychiatric Epidemiology, 51, 339-348. doi: 10.1007/s00127-016-1178-7

Neff, K. D. (2003a). Self-compassion: An alternative conceptualization of a healthy attitude toward oneself. Self and Identity, 2, 85-101. doi: 10.1080/15298860309032

Neff, K. D. (2003b). The development and validation of a scale to measure self-compassion. Self and Identity, 2, 223-250. doi: 10.1080/15298860309027

Neff, K., \& Germer, C. (2013). A pilot study and randomized controlled trial of the Mindful Self-Compassion Program. Journal of Clinical Psychology, 69, 28-44. doi: 10.1002/jclp.21923

Neff, K., \& McHehee, P. (2010). Self-compassion and psychological resilience among adolescents and young adults. Self and Identity, 9, 225-240. doi: 10.1080/15298860902979307

Petrocchi, N., Ottaviani, C., \& Couyoumdjian, A. (2014). Dimensionality of self-compassion: Translation and construct validation of the self-compassion scale in an Italian sample. Journal of Mental Health, 23, $72-77$. doi: 10.3109/09638237.2013.841869

Raes, F. (2010). Rumination and worry as mediators of the relationship between self-compassion and depression and anxiety. Personality and Individual Differences, 48, 757-761. doi: 10.1016/j.paid.2010.01.023

Relyea, M., \& Ullman, S. E. (2015). Measuring social reactions to female survivors of alcohol-involved sexual assault. Journal of Interpersonal Violence, 30, 1864-1887. doi: 10.1177/0886260514549054

Rose, A. V., \& Rimes, K. A. (2018). Self-criticism self-report measures: Systematic review. Psychology and Psychotherapy, 91(4), 450-489. doi: 10.1111/papt.12171

Schroeder, M. A., Lander, J., \& Levine-Silverman, S. (1990). Diagnosing and dealing with multicollinearity. Western Journal of Nursing Research, 12(2), 175-187. doi: 10.1177/019394599001200204

Scoglio, A. A. J., Rudat, D. A., Garvert, D., Jarmolowski, M., Jackson, C., \& Herman, J. L. (2015). Self-compassion and responses to trauma: The role of emotion regulation. Journal of Interpersonal Violence, 33(13), 20162036. doi: $10.1177 / 0886260515622296$

Stuart, H., Chen, SP, Krupa, T., Narain, T., Horgan, S., Dobson, K. \& Stewart, S. H. (2019). The Caring Campus Project Overview. Canadian Journal of Community Mental Health, 37, 69-82.

Tanaka, M., Wekerle, C., Schmuck, M. L., Paglia-Boak, A., \& The MAP Research Team (2011). The linkages among childhood maltreatment, adolescent mental health, and self-compassion in child welfare adolescents. Child Abuse \& Neglect, 35, 887-898. doi: 10.1016/j.chiabu.2011.07.003

Testa, M., VanZile-Tamsen, C., Livingston, J., \& Koss, M. (2004). Assessing women's experiences of sexual aggression using the Sexual Experiences Survey: Evidence for validity and implications for research. Psychology of Women Quarterly, 28, 256-265. doi: 10.1111/j.1471-6402.2004.00143.x

Thompson, B. L., \& Waltz, J. (2008). Self-compassion and PTSD symptom severity. Journal of Traumatic Stress, 21, 556-558. doi: 10.1002/jts.20374

Trompetter, H. R., de Kleine, E., \& Bohlmeijer, E. T. (2017). Why does positive mental health buffer against psychopathology? An exploratory study on self-compassion as a resilience mechanism and adaptive emotion regulation strategy. Cognitive Therapy Research, 41, 459-468. doi: 10.1007/s10608-016-9774-0

Ullman, S. E., \& Filipas, H. H. (2001). Predictors of PTSD symptom severity and social reactions in sexual assault victims. Journal of Traumatic Stress, 14, 369-389. doi: 10.1023/A:1011125220522

Ullman, S. E., \& Najdowski, C. J. (2010). Understanding alcohol-related sexual assaults: Characteristics and consequences. Violence and Victims, 25, 29-44. 
Valdez, C. E., \& Lilly, M. M. (2016). Self-compassion and trauma processing outcomes among victims of violence. Mindfulness, 7, 329-339. Retrieved from: https://link.springer.com/article/10.1007/s12671-0150442-3.

Vettese, L. C., Dyer, C. E., Li, W. L., \& Wekerle, C. (2011). Does self-compassion mitigate the association between childhood maltreatment and later emotion regulation difficulties. International Journal of Mental Health and Addiction, 9, 480-491. doi: 10.1007/s11469-011-9340-7

Weiss, K. G. (2010). Too ashamed to report: Deconstructing the shame of sexual victimization. Feminist Criminology, 5, 286-310. doi: 10.1177/1557085110376343

Werner, K., Jazaieri, H., Goldin, P., Ziv, M., Heimberg, R., \& Gross, J. (2012). Self-compassion and social anxiety disorder. Anxiety, Stress, and Coping, 25, 543-558. doi: 10.1080/10615806.2011.608842

West, S., Aiken, L., \& Krull, J. (1996). Experimental personality designs: Analyzing categorical by continuous variable interactions. Journal of Personality, 64, 1-48. doi: 10.1111/j.1467-6494.1996.tb00813.x

Windle, G. (2011). What is resilience? A review and concept analysis. Reviews in Clinical Gerontology, 21(2), 152169.

Xu, Y., Olfson, M., Villegas, L., Okuda, M., Wang, S., Liu, S., \& Blanco, C. (2013). A characterization of adult victims of sexual violence. Psychiatry, 76, 223-240.

Yarnell, L., Stafford, R., Neff, K., Reilly, E., Knox, M., \& Mullarkey, M. (2015). Meta-analysis of gender differences in self-compassion. Self and Identity, 14, 1-22. doi: 10.1521/psyc.2013.76.3.223

Zeller, M., Yuval, K., Nitzan-Assayag, Y., \& Bernstein, A. (2015). Self-compassion in recovery following potentially traumatic stress. Journal of Abnormal Child Psychology, 43, 645-653. doi: 10.1007/s10802-014-9937-y 